\title{
Application Status and Development Trend of Power Consumption Information Collection System
}

\author{
ZHU Enguo, LIU Xuan and ALIAOSHA Ye \\ China Electric Power Research Institute, Beijing 100192, China \\ enguozhu@163.com
}

\begin{abstract}
Keywords: Power consumption information collection system, smart grid, step tariff, bidirectional interaction, information and communication
\end{abstract}

\begin{abstract}
Power consumption information collection system is an important part of building smart grid. It introduced the composition structure of power consumption information collection system and analyzed its construction status and application requirements at home and abroad. It discussed the massive data processing, the standardization of carrier communication, prepaid control, diversified tariff, information security protection and other key technologies. At last, the proposals were presented to steadily push forward the construction of power consumption information collection system.
\end{abstract}

\section{Introduction}

With the progress of science and technology and the variation of energy development pattern, the development of economy and society depends on more electric power energy than ever. Power industry is facing unprecedented opportunities and challenges, including global warming, depleted fossil energy, heightened awareness of the ecological civilization, more increasing distributed power generation resources. Society puts higher requirements to safety, reliability and service quality of power supply. Therefore, relying on modern information, communication and control technology to actively develop smart grid and transform development mode of power grid has become the common choice of the international power industry to respond to the future challenges[1]-[5].

The future smart grid will obtain informationization and intelligence in its operation and control. So it can improve the energy structure and utilization efficiency, meet the diverse needs of electric power application, improve the economy, safety and reliability of power transmission [6]-[9]. To improve the level of electric power informationization, according to their respective demands electric power corporations have built load management system and concentrated meter reading system in recent years. These systems have played an active role in safe production and management. But they are small, decentralized and isolated. The overall collection coverage rate is low. They cannot form an integrated collection platform to cover all the users. So SGCC made the strategic decisions of comprehensively constructing the power consumption information collection system in 2009.

According to the uniform standards and programs, now SGCC is putting all efforts to push up the construction of collection system. It described the composition structure and application status of power consumption information collection system, focused on its key technologies and development trends. At last, it put forward some suggestions about the construction of collection system.

\section{Composition Structure of Power Consumption Information Collection System}

Power consumption information collection system is the physical basis of constructing smart grid. It uses advanced sensor, communication, automatic control and other technologies to collect and manage data, analyze power quality and line loss statistical data. It can timely collect electric energy information, find abnormal power consumption, monitor and control electricity load. It can provide technical support for achieving step tariff, pre-paid control and other marketing service strategies.

As shown in Fig.1, the power consumption information collection system is composed by main station, communication channel and collection devices. Main station is composed by database server, 
disk array, application server, front-end server, interface server, workstation, GPS clock, firewall and other related network equipments. It is used to complete business application, data collection, control, front-end communication dispatch, database management and other functions. Communication channel includes fiber private network, GPRS/CDMA wireless public network, $230 \mathrm{MHz}$ wireless private network and so on. It is used to transfer data from collection devices to main station. Collection devices include collection terminal for special transformer, concentrator, collector, smart meter and so on. They are installed to collect and provide initial power consumption information of the whole system.

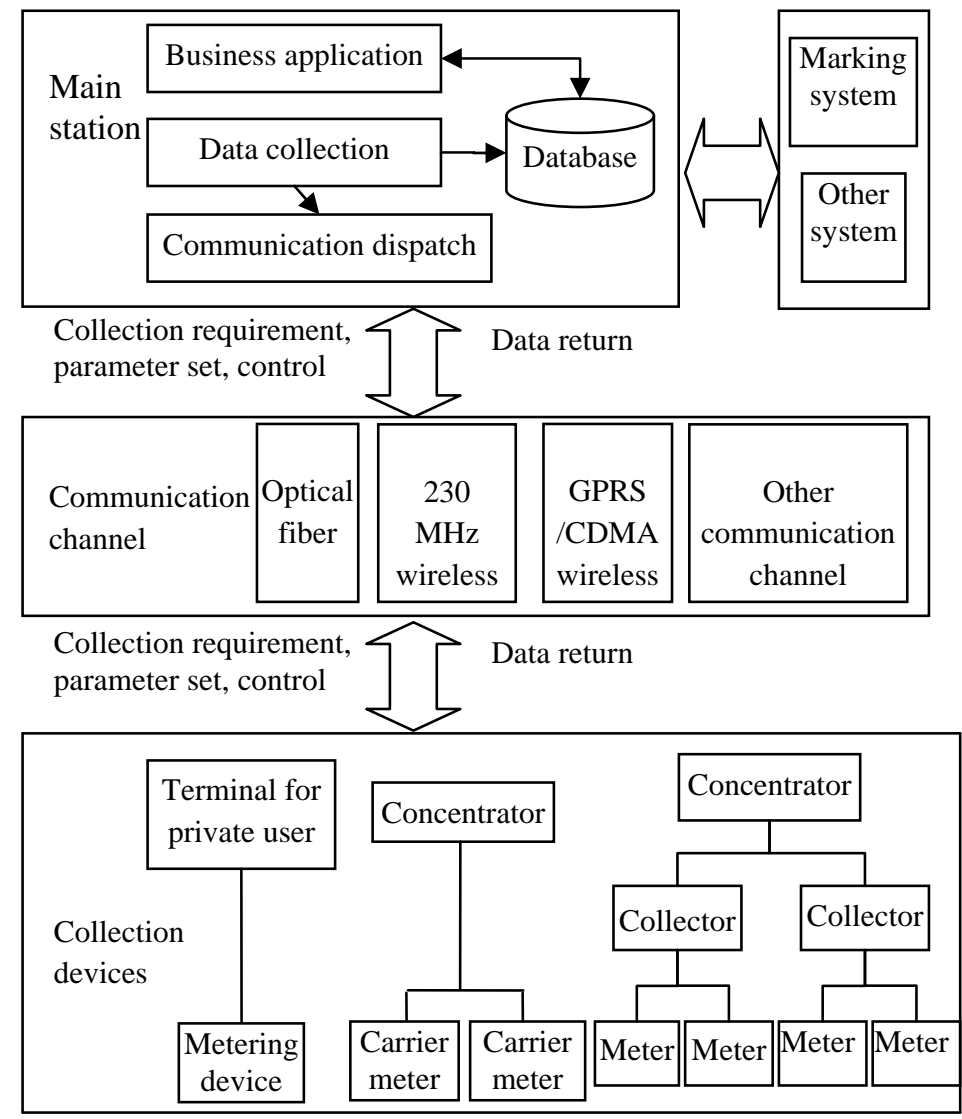

Fig.1 The composition structure of power consumption information collection system

\section{Application Status of Power Consumption Information Collection System}

Application Status of Foreign Power Consumption Information Collection System. The development of science and technology continuously promotes the technical innovation and efficient management of power industry. To meet the needs of photovoltaic, wind power, biomass power generation and distributed power supply, the Europe, USA and other developed countries researched and explored the power consumption information collection technology, which can further improve the quality of electricity services, the operation efficiency of power grid and achieve the purpose of energy saving. In the 1980s, the large industrial users began to use the automatic meter reading system. Now these technologies gradually developed into advanced metering infrastructure[10].

In 2006, the council of European Union published an energy green book called "sustainable, competitive, secure Europe's energy strategy"[11]. It proposed that the main direction of the EU's future power grid construction was smart grid and presented the construction object of smart power consumption service. It could adjust the local power consumption demand and control load by automatic meter management system.

Italian electric power company reformed and installed 31.8 million smart meters in 2001 and established smart measurement network [12]. But the core technology of the smart network is only the electronic meter with the function of measuring the peak and valley power energy. 
Since 2008, France electric power company replaced 27 million ordinary power meters by smart meters, which allows users to automatically track their electricity consumption status and remotely control their electrical equipments. More than 10 million users could receive the peak and valley electricity price information by the web site, e-mail, telephone and specialized electronic receiver and timely adjust their power consumption mode.

To meet the access of distributed energy such as solar the Spanish power company (ENDESA) began to construct the smart city and automatic meter reading system. In 2014, all the power distribution operators must have automatic meter reading management system in operation. All the electromechanical meters should be replaced by the smart meters before 2018. ENDESA company has 15.5 million meters and presently it has installed more than 10,000 smart meters.

Boulder City in Colorado has built the first smart grid city of the United States in 2008. It installed smart meters for all the users so they could obtain tariff information, automatically adjust power consumption time. On January 25, 2009, the White House released a recovery plan scale report that planned to install 40 million smart meters with remote meter reading and management functions. It has installed more than 15 million smart meters in 2010 and plans to install 52 million smart meters in 2013. The popularizing rate of smart meter will reach 50 percent in 2015.

Application Status of Power Consumption Information Collection System in China. With the deepening of power market reform, the collection method of the residential power consumption information has also undergone great changes. The manual meter reading and charging method can not meet the requirements of modern management. The remote centralized meter reading technology has become the hot research topic at home and abroad[13]-[16].

Since the 1990s, China's power companies has established power energy information collection system including gate power energy collection system, power load management system, low voltage centralized meter reading system and distribution automation systems. But these systems were constructed by province or city company and lack of unified planning and standards. It could only collect the part of user's power consumption information and obtain the primary function application. The marketing personnel could not timely, accurately and comprehensively obtain all the users' power consumption information and could not meet the needs of the marketing business applications.

In order to meet the requirements of the electricity market operation and business modernization, it need construct power consumption information collection system and enhance the intensive, lean and standardization management level. In September 2008, SGCC began to study the standardization construction project of metering, meter reading and charges. Within the company system, it unified the technical specifications of smart meter and collection device and defined their appearance, function, reliability, communication protocol, information exchange security certification, acceptance testing and other aspects.

Since 2009, SGCC established the construction object of full coverage, collection and charge control. According to the principle of unified plan, standard and implementation, it began to construct power consumption information collection system. By the end of April 2012, SGCC has installed 83.52 million smart meters and the whole system covered 88.5 million users. At present, the main station of 27 provinces have been established and put into operation. The data have been applied in a number of business applications such as the meter reading charges, line loss analysis, business expanding, fault repairing, orderly power consumption, interactive services, power trading, distribution network operation and power quality monitoring.

\section{The Key Technology of Power Consumption Information Collection System}

Mass Data Processing Technology. The business area of SGCC covers 27 provinces and the number of users in the operating range is over 300 million. At present, it is popularizing smart meter and the power consumption information collection system, which establishes a full-service data model to achieve the comprehensive utilization of the data and advanced applications of the function. Due to the massive users and a large amount of data, it need use large capacity data processing technology, load balancing technology, disaster backup technology and spatial database engine 
technology to process concurrent of huge amounts of data and multi-task and improve the operation reliability of the main station.

Standardization of Carrier Communication. Currently, carrier communication technology applications have different technical characteristics. It is very necessary to research the feasibility of communication standardization technology. According to the main technical characteristics and parameters such as center frequency, modulation method, occupied bandwidth, the maximum transmission level, transmission protocol, router algorithm, related technical test and parameter measurement method, the technical standard infrastructure should be presented to make collection devices join, connect and exchange each other.

Smart Pre-paid Control Technology. With the improvement of power information level and development of marketing business, power consumption information collection system uses management mode based on smart pre-paid control technology. Customers firstly pay the electricity bill to ensure their power consumption. The collection system collects power consumption information, computes remain fee and displays it to customers. If there is no much fee, it will remind customers to pay the electricity bill. It will perform break off power consumption when there is no fee. Pre-paid management can be performed by the main station, collection device and smart meter. Its application area and work requirements are shown as Table 1.

Table 1 Pre-paid control mode comparison

\begin{tabular}{|l|l|l|l|}
\hline Pre-paid method & \multicolumn{1}{|c|}{ Main station pre-paid } & Collection device pre-paid & \multicolumn{1}{|c|}{ Smart meter pre-paid } \\
\hline $\begin{array}{l}\text { Logic perform } \\
\text { lace }\end{array}$ & $\begin{array}{l}\text { Main station perform pre-paid control } \\
\text { logic }\end{array}$ & $\begin{array}{l}\text { Collection device perform } \\
\text { pre-paid control logic }\end{array}$ & $\begin{array}{l}\text { Smart meter perform pre-paid } \\
\text { control logic }\end{array}$ \\
\hline Application area & $\begin{array}{l}\text { Private transformer user, the single or } \\
\text { three phase industrial or commercial } \\
\text { user, residential customer }\end{array}$ & $\begin{array}{l}\text { Private transformer user, but } \\
\text { has large error }\end{array}$ & $\begin{array}{l}\text { Residential customer, reduce } \\
\text { pressure of main station with } \\
\text { huge number of users }\end{array}$ \\
\hline
\end{tabular}

Diverse Tariff Implementation Technology. Now the scale application of smart meter is rapidly advancing. The ladder price and time sharing price policy will be fully implemented. It encourages customers to reasonably plan power consumption time and improve the utilization efficiency of power resources. The tariff of each segment in the price ladder changes with different segment. The tariff in the time sharing price changes with load variation and different time segment. The implementation of the ladder price and time sharing price puts forward higher requirements to the accuracy and reliability of smart meter's clock. It need take technical measures such as clock calibration, inspection, maintenance and fault analysis to make the clock of the main station, production scheduling system of provincial metrology center, smart meter and collection device accurate and reliable.

Security Protection Technology of Power Consumption Information. The power consumption information collection system collects a large amount of information and covers a wide range. Safety risks will threaten security, stability and economy operation of power system. The power consumption information collection system is one of the most core business application systems. The information of customer and power consumption is the core data resource of power industry, which involves all aspects of social life. Illegal using or leaking information will bring irreparable damage. So it is very necessary to research the security protection status of the power consumption information collection system, analyze and assess the potential security problems in all the aspects of the collection system and propose security protection construction program.

\section{Summary}

The power consumption information collection system is inevitable requirements to build marketing infrastructure and smart grid, change the development method of SGCC and power grid. It can effectively improve automation level of the energy metering, automatic meter reading, smart pay control and meet the needs of SG186 deepening the business application. It can provide support to develop new energy, perform the ladder price and bidirectional interaction service. It is of great 
importance to optimize resource allocation, promote energy saving, lead technology innovation, drive industry upgrading and ensure the economic and social sustainable development.

\section{References}

[1] LIU Zhenya: Smart Grid, China Electric Power Press(2010)

[2] YU Yixin and LUAN Wenpeng: Smart Grid and Its Implementations, Proceedings of the CSEE, Vol.29, no.34 (2009), p.1-8

[3] United States Department of Energy Office of Electric Transmission and Distribution: The Smart Grid: an Introduction. http://www.oe.energy.gov/DocumentsandMedia/DOE_SG_Book_Single Pages(1).pdf

[4] European Commission. European Technology Platform Smart-grids: Vision and Strategy for Europe's Electricity Networks of the Future. http://ec.europa.eu/ research/energy/pdf/smartgrids _en.pdf

[5] YANG Dechang, LI Yong, C.Rehtanz, LIU Zehong and LUO Longfu: Study on the Structure and the Development Planning of Smart Grid in China, Power System Technology, Vol.33, no.20(2009), p.13-20

[6] ZHANG Wenliang, LIU Zhuangzhi and WANG Mingjun: Research Status and Development Trend of Smart Grid, Power System Technology, Vol. 33, no. 13(2009), p. 1-11

[7] WANG Chengshan and LI Peng: Development and Challenges of Distributed Generation, the Micro-grid and Smart Distribution System, Automation of Electric Power Systems, Vol. 34, no. 2(2010), p. 10-14

[8] XIAO Shijie: Consideration of Technology for Constructing Chinese Smart Grid, Automation of Electric Power Systems, Vol.33, no.9(2009), p.1-4

[9] CHANG Kang, XUE Feng and WANG Weidong: Review on the Basic Characteristics and its Technical Progress of Smart Grid in China, Automation of Electric Power Systems, Vol.33, no.17(2009), p.10-15

[10]Hart D G: Using AMI to Realize the Smart Grid. IEEE Power and Energy Society General Meeting-Conversion and Delivery of Electrical Energy in the 21st Centry. Pittsburgh, Pennsylvania, USA, 2008

[11]Commission of the European Communities. GREEN PAPERS: A European Strategy for Sustainable, Competitive and Secure Energy. http://ec.europa.eu/energy/green-paper-energy/ doc/2006_03_08_pg_document_en.pdf

[12] ZHONG Jin, ZHENG Ruimin, YANG Weihong and Felix Wu: Construction of Smart Grid at Information Age, Power System Technology, Vol.33, no.13(2009), p. 12-18

[13]CHEN Shuyong, SONG Shufang and LI Lanxin: Survey on Smart Grid Technology, Power System Technology, Vol. 33, no. 4(2009), p. 1-7

[14]ZHANG Jingchao and CHEN Zhuoya: The Impact of AMI on the Future Power System, Automation of Electric Power Systems, Vol. 34, no. 2(2010), p. 20-23

[15] Anon: Advanced Metering Infrastructure. National Energy Technology Laboratory(2008)

[16] Anon: AMI Technology Trials Report, Australia: Department of Primary Industries(2007) 